\title{
MINIMAX INEQUALITY FOR THE PREDICTION RISK
}

\section{GAJEK AND V. LIPIŃSKA}

Abstract. This is a continuation of the article "Sharp inequality for the Bayes prediction risk" (2007). But, instead of the Bayes prediction problem, the minimax one is considered in this paper. The lower bound for the minimax prediction risk is derived by using the information inequality. Moreover it is shown that a predictor $\delta(X)$ for which the lower bound is attained is a minimax one. Sufficient conditions for the admissibility of predictors are also given.

Mathematics subject classification (2010): 62F15, 62M20.

Keywords and phrases: Prediction; minimax risk function; information inequality.

\section{REFERENCES}

[1] B. Z. Bobrovsky, E. MAYER-Wolf, AND M. ZAKaI, Some classes of global Cramér-Rao bounds, The Annals of Statistics 15, 1421-1438, (1987).

[2] D. Brown, AND L. GaJeK, Information inequalities for the Bayes risk, The Annals of Statistics 18, 1578-1594, (1990).

[3] P. Diaconis, AND D. Ylvisaker, Conjugate priors for exponential families, The Annals of Statistics 7, 269-281, (1979).

[4] L. GAJEK, An improper Cramer-Rao lower bound, Applicationes Mathematicae 19, 241-256, (1987).

[5] L. GAJEK, On the minimax value in the scale model with truncated data, The Annals of Statistics 16, 669-677, (1988).

[6] L. GAJeK, AND M. KaŁuszKa, Nonexponential applications of a global Cramer-Rao inequality, Statistics 26, 111-122, (1995).

[7] L. GAJEK, AND V. LIPIŃSKA, Sharp inequality for the Bayes prediction risk, Inequality Theory and Applications, Vol. 5, 97-106, (2007)

[8] E. L. Lehmann, And G. Casella, Theory of Point Estimation, Second edition, Springer, (1998)

[9] R. W. Miller, AND C. B. ChANG, A modified Cramér-Rao bound and its applications, IEEE Trans. Inform. Theory, IT-24, 398-400, (1978).

[10] Y. TAKADA, Lower bound on the Bayes risk for statistical prediction problems, Comm. Statist. Theory Methods 28, 693-703, (1999).

[11] H. VAn Trees, Detection, Estimation and Modulation Theory 1, Wiley, New York, (1968).

[12] S. TrybuŁA, Minimax mutual prediction, Applicationes Mathematicae XXVII, 4, 437-444, (2000).

[13] S. TRYBuŁA, Minimax mutual prediction of multinomial random variables, Applicationes Mathematicae XXX, 4, 371-377, (2003). 